Karin Kukkonen

\title{
Bayesian Narrative: Probability, Plot and the Shape of the Fictional World
}

\begin{abstract}
Probability' seems to be a term forgotten by literary theory. Central to neoclassical and Augustan criticism, probability describes the inferences of readers and their developing discernment of what is likely to happen in a narrative (Patey 1984). This article proposes to bring probability back into the current debates in narratology and literary theory by drawing on recent advances in probabilistic, Bayesian approaches to different aspects of human cognition. Considering the example of Frances Burney's novel Evelina (1778), it presents a Bayesian model for the analysis of narrative through the ways in which the encounter with the text shapes readers' probability judgements. A narrative's 'probability design' cues readers to revise or maintain their expectations for its further development and leads readers to accept outcomes as inevitable that seemed distinctly unlikely at the beginning of the narrative (such as Evelina's brilliant marriage to the aristocrat Lord Orville in Burney's novel). Reconsidering narrative from a Bayesian, probabilistic point of view offers new perspectives on the emotional investments of readers in narrative, as well as plot and verisimilitude.
\end{abstract}

Karin Kukkonen, University of Turku

E-Mail: karin.kukkonen@utu.fi

\section{Introduction}

When readers put down Frances Burney's novel Evelina (1778), they have come to accept events which looked distinctly unlikely when the story began: a young lady, who had grown up in the countryside without urbane education or pretensions to fame and fortune, marries a heartthrob aristocrat, is relieved from the status of a bastard and becomes heiress to a considerable fortune. This is certainly not an uncommon plot development in literary narrative, but what makes readers accept such a dramatic change in probabilities? What makes readers think, when they arrive at the happy ending, that in fact this was the most feasible course the story could have taken? There seems to be more at stake than just genre conventions. Something happens to readers' sense of probability when they engage with a literary narrative, and as anecdotal evidence suggests, the way in which a narrative 
treats readers' probability judgements contributes significantly to whether it is seen as successful. The present article draws on current Bayesian, probabilistic approaches to cognition in order to shed light on how readers' developing sense of probability and their emotional appraisal of narrative events is cued by the 'probability design' of a particular narrative. It investigates the dynamics of readers' probability judgements and develops a new perspective on the narratological concepts of plot and storyworld on the basis of a Bayesian understanding of narrative.

\section{Reading as a Bayesian Learning Process}

In recent years, Bayesian approaches have changed the way psychologists understand a broad array of cognitive processes (see Frith 2007: 85-138 for an overview). Such a Bayesian approach suggests that the human mind gets a grip on the formidable complexity of our natural and cultural environments through its probability calculus. For example, when learning a language, it seems that toddlers establish a sense of likely syllable sequences to distinguish between individual words rather than operate by rote learning or by trial and error. If you imagine the previous sentence spoken out aloud, they learn that (in English) 'todd-' is likely to be followed by '-lers', but that '-lers' is not likely to be followed by '-est', and this allows them to parse the stream of speech into likely syllable heaps which constitute words (see Saffran, Senghas and Trueswell 2001). Such a learning process relies on incremental improvements of our sense of the probabilities that govern the linguistic, cultural and natural environment we move in. It provides the human mind very quickly with a good enough predictive model to interact with the environment, and whenever these predictions are contradicted (that is, if the word 'lers-est' came into existence), the probabilistic model is updated on the basis of these new observations. This process of revising beliefs about the likely structure of our environment is called 'Bayesian inference', because the way it reconfigures the probabilities involved has been formalised by the mathematician Thomas Bayes in the mid-eighteenth century. ${ }^{1}$ Bayesian approaches to cognition understand human thinking and learning processes through such Bayesian inferences.

What does it mean, then, to think of narrative in Bayesian terms? When readers open a book and encounter a new fictional world, this might be under-

1 Bayes' theorem takes the mathematical form $\mathrm{P}(\mathrm{A} \mid \mathrm{B})=\mathrm{P}(\mathrm{B} \mid \mathrm{A}) \bullet \mathrm{P}(\mathrm{A}) / \mathrm{P}(\mathrm{B})$ with $\mathrm{A}$ being the prior hypothesis about the environment, $B$ being the new observation and $\mathrm{P}(\mathrm{B} \mid \mathrm{A})$ being the likelihood of making observation B in an environment for which A holds true. 
stood as a process of establishing and revising beliefs about the environment of the fictional world on the strength of the evidence at hand. Novels like Evelina, subtitled The History of a Young Lady's Entrance into the World, enact this learning process in the experience of the main character who needs to figure out how to navigate the social world of the ballrooms and pleasure gardens of 1770 s London. Let us join the heroine as she attends her first ball:

We were all sitting in this manner, [Lord Orville] conversing with all gaiety, I looking down with all foolishness, when that fop who had first asked me to dance, with a most ridiculous solemnity, approached, and after a profound bow or two, said, 'I humbly beg pardon, Madam, -and of you too, my Lord,-for breaking in upon such agreeable conversation-which must, doubtless, be much more delectable-than what I have the honour to offer-but-'

I interrupted him-I blush for my folly,-with laughing; yet I could not help it, for, added to the man's stately foppishness, (and he actually took snuff between every three words) when I looked round at Lord Orville, I saw such extreme surprise in his face, - - the cause of which appeared so absurd, that I could not for my life preserve my gravity.

I had not laughed before from the time I had left Miss Mirvan, and I had much better have cried then; Lord Orville actually stared at me; the beau, I know not his name, looked quite enraged. 'Refrain-Madam,' (said he, with an important air,) 'a few moments refrain!-I have but a sentence to trouble you with.-May I know to what accident I must attribute not having the honour of your hand?'

'Accident, Sir!' repeated I, much astonished.

'Yes, accident, Madam-for surely,-I must take the liberty to observe-pardon me, Madam, -it ought to be no common one-that should tempt a lady-so young a one too,--to be guilty of ill manners.'

A confused idea now for the first time entered my head, of something I had heard of the rules of assemblies; but I was never at one before-I have only danced at school,--and so giddy and heedless I was, that I had not once considered the impropriety of refusing one partner, and afterwards accepting another. (Evelina 2008: 34-35)

Evelina draws a lively picture of the "stately foppishness" of the beau with his snuff-taking, stilted speech and overdrawn politeness. Because she cannot easily make sense of his behaviour, she casts him as a ridiculous misfit. She laughs at the fop and rejects his (facetious) offer to make a polite withdrawal in the exchange by declaring her dance with Lord Orville an "accident". The situation gets awkward when two questions remain unanswered: Why is the fop so offended? And why does Lord Orville sport such "extreme surprise"? But there is more at stake than what Noël Carroll (2007) calls 'erotetic narrative', that is, the move between raising questions about the fictional world and offering answers to readers as they make their way through the narrative. Sure enough, the questions of the fop's behaviour and Lord Orville's surprise are answered by the end of the passage, but these answers come through the reconfiguration of the way in which Evelina conceives of the entire situation in the ballroom. Only when the thought of the "rules of assemblies" comes into her mind does Evelina realise that she might be the one at 
fault here, and the probabilities that govern this exchange have to be drastically reconfigured. In an environment in which the "rules of assemblies" are in power, the probability of the fop's taking offense is indeed very high, and as Evelina begins to understand this, she has to realise that her behaviour has been the cause of his justified displeasure. The "absurd" situation of the ridiculous caricature suddenly turns into a very real embarrassment for the young lady, as she begins to understand the actual stakes informing this exchange.

Here, as elsewhere in the novel, the character Evelina enacts Bayesian inferences which in other novels readers might be privileged to. Both Evelina and her readers develop a predictive grasp of the probabilities of the fictional world very quickly. As the plot reveals new, unpredicted information to them, they revise their beliefs and develop their probabilistic model of the fictional world further. This process constitutes something more global than filling a gap (in Iser's model) or answering a question (in Carroll's or Bordwell's models) here, as the entire shape of the fictional world is reconfigured by readers. Bayesian inferences in narratives create a feedback loop between readers' sense of the probabilistic shape of the fictional world and what they find on the page. Evelina's lively prose, her detailed description of the "ridiculous solemnity" and the "profound bow" of the beau, and her rendition of his convoluted speech, give readers a very precise sense of her probabilistic model of the fictional world (and, in turn, inform their own), which presents her with a whole range of predictions to be developed in the further development of the scene. A Bayesian perspective therefore moves away from the abstract, forensic way of conceiving of narrative as a game of question and answer, and enters the realm of thick description of the reading experience.

Bayesian inferences often work below the level of awareness which propositional deliberations, such as Evelina's puzzlement by the fop's behaviour, require. For example, when Evelina "looked round at Lord Orville" it seems clear that she turns to him to establish rapport. What she sees, however, is not a conspiratory twinkle but "extreme surprise", which makes the whole situation even more "absurd”. Without verbalising, Burney indicates Evelina's predictions (about Orville's support) in her bodily movements. Indeed, according to the so-called 'predictive coding' account, it is first and foremost through the predicted effects of the body's movements that the human mind can make sense of an environment (see Clark 2013 for a current overview). What the human body senses through sensorimotor systems then feeds into higher-level probabilistic models of perception, which in turn feed into higher-level probabilistic models of more propositional thinking. The feedback loop between information from the text and the probabilistic predictive shape of the fictional world can be specified through such "cascades of cognition" (see Kukkonen forthcoming), and this allows for a fine-grained analysis of how the shape of the fictional world predicts and is corrected as a probabilistic model. 
It is not unusual that readers find different probabilistic models for the fictional world, which compete. So far, I have considered Evelina's inferences to the extent that they are parallel to those of readers. However, while the heroine herself remains for some time blissfully oblivious of the grave social faux pas she has committed, readers know that Evelina has it coming right from the start of the passage. After all, she is telling these events with hindsight in a letter, and the way in which she interrupts her narrative discourse and re-evaluates her inferences suggests that she has had to revise her beliefs in the course of events. In the first half of the passage, her assessments shift between those of the Evelina in the ballroom who finds the fop "ridiculous" and the situation "absurd", and those of the Evelina at the desk who considers the situation in the light of polite behaviour and "blush[es] for [her] folly". This juxtaposition of narrative perspectives adds additional drama to the scene, because the interference from the higher-level narratorial perspective, which works with the benefit of hindsight, suggests to readers that a revision of the probabilistic structure is likely to ensue without fully actualising it. In the instance of Evelina, such juxtapositions between the probabilities of readers and those of characters are inscribed in the set-up of the epistolary novel, but narrators in other forms, too, can - depending on their rhetorical temperament - suggest, insinuate or negate a reconfiguration of the probabilities of the fictional world.

\section{Probabilities of the Fictional World}

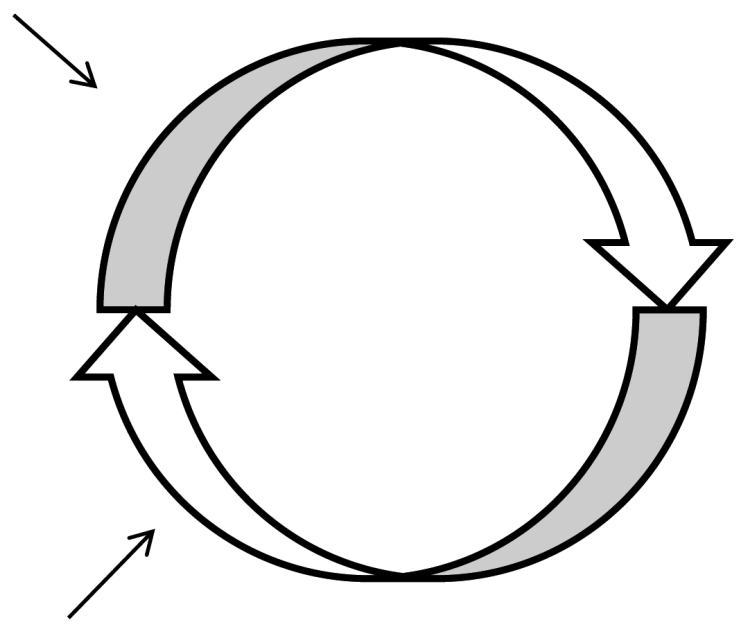

Plot

Figure 1: Probability Design 
Considering narrative from a Bayesian perspective thus posits the fictional world as a work in progress. As readers move through the narrative, they revise their beliefs about the shape of the fictional world and (usually) get a progressively better grasp of its probabilities. Everything they read, from small-scale bodily movement to general propositional statement, contributes to the predictive thinking of the Bayesian reader. It feeds into the loop between prior hypotheses about the probabilities of the fictional world and the new observations which the plot presents to readers (see Figure 1). Even though Bayesian inferences in reading are by themselves not different from real-world Bayesian inferences, there seems to be a shift in emphasis: In the psychology of learning and in the models of predictive coding from the psychology of perception, the goal of Bayesian inferences is to establish a stable model of the world with predictions as reliable as possible. The world, of course, will continue to surprise us. Narratives, in turn, are designed to enable constantly new, unpredicted observations and thus reconfigure the probabilities of the fictional world. If somebody gave Evelina the "book of laws and customs à-la-mode" (Evelina 2008: 84) which she wishes for, there would be no story to tell. A Bayesian perspective on narrative therefore investigates what I call 'probability design' - the ways in which the feedback loop between the probabilities of the fictional world and the pacing of new observations through the plot is constructed so that it keeps readers involved in making sense of the events of the narrative.

\section{Probability Design through Surprise, Curiosity and Suspense}

A Bayesian analysis of narrative asks questions such as what are the predictions and when do they need to be recalibrated in order to establish the probability design of the narrative. In this section, I will consider the second question and the dimension of plot in greater detail before moving to a discussion of predictions, probability and verisimilitude in the next section.

Plot is notoriously difficult to define. It seems to lie between the bare-bone events of the narrative, that is, the story, and its detailed texture, that is, the discourse. With Aristotle, it can be seen as the arrangement of story events in the order in which they occur in discourse. This arrangement enables the process by which the discourse leads readers to establish causal and temporal connections between story events. The ordering of events, as narratologists from Meir Sternberg (1978) to Raphaël Baroni (2007) have pointed out, has very distinct cognitive effects through the ways in which information is disclosed to readers. Sternberg cate- 
gorises these cognitive effects 'surprise', 'curiosity' and 'suspense'. In a Bayesian perspective on narrative, plot becomes the pacing of observations about the fictional world, and these 'cognitive effects' can be reassessed as stages of Bayesian inference shaped by probability design. As we shall see, a closer attention to surprise, curiosity and suspense will indicate when and how predictions are recalibrated.

Even though Sternberg includes the notion of 'probability' in his fascinating readings of how readers' expectations are manipulated in the Odyssey, Fielding and Austen (see e.g. 1978: 66-78, 130-137), as curiosity, suspense and surprise take centre-stage in later publications as 'narrative universals' (2001; see also 2003), it becomes clear that he understands them primarily as temporally-directed instances of gap-filling in exposition rather than recalibrating probabilities. The key features are perhaps most concisely captured in the minimal story of Brewer and Lichtenstein (1981; they adopt Sternberg 1978 in an empirical experiment), where story events get rearranged in three different ways:

(1) Butler puts poison in wine.

(2) Butler carries wine to Lord Higginbotham.

(3) Lord Higginbotham drinks wine.

(4) Lord Higginbotham dies. (Brewer and Lichtenstein 1981: 8)

If only the last sentence is disclosed to readers, they experience surprise because Lord Higginbotham dies without any indication of a cause, and they are therefore made aware of a gap in the narrative. If readers are given sentences (2)-(4), they experience curiosity, which Sternberg characterises as a backward-directed mental operation, because they are trying to fill the gap of what happened before the events they know about. If they are given sentences (1)-(3), the cognitive effect is suspense, which Sternberg characterises as a forward-directed mental operation, because here readers are trying to guess how the situation will turn out in the future.

While Sternberg acknowledges that all three cognitive effects lead to readers' "construction of rival hypotheses" (1992: 532), he always sees them connected with gaps. A Bayesian perspective on surprise, curiosity and suspense, on the other hand, focuses on the possibilities which readers see and, more particularly, on the predictive power which they assign, turning possibilities into probabilities. If Lord Higginbotham dies, there is a range of possibilities to explain this event. As readers learn more about the fictional world, these possibilities are weighted to yield different predictive probabilities which develop with the observations that readers are led to make in the course of the narrative. More information about the butler, his whereabouts during the Lord's death and his ordering arsenic the day before, will make the possibility that he kills the Lord more and more likely. 
As this thumbnail sketch shows, also in a Bayesian model, surprise, curiosity and suspense serve as a motor of plot development, because they detail how a narrative shapes and reshapes readers' sense of the probabilities of the fictional world. Furthermore, as shall become apparent from the more detailed discussion of these cognitive effects below, in a Bayesian model, surprise, curiosity and suspense are commensurable, the one leading to the other, and deeply entwined with readers' emotional investments.

In Evelina, it all begins with surprise. Lord Orville's "extreme surprise" at the fop's accusations occurs because he thinks of Evelina as a delightfully unpretentious partner in dance and conversation. To him, the probability that she wilfully snubbed the fop seems very slim indeed, and the fop's claims force him to reconsider his sense of likelihood. In Bayesian terms, surprise ensues whenever we make a new observation that enforces a reconfiguration of the prior probabilities we work with. Theories from the cognitive sciences which model human interaction with the world in terms of Bayesian inferences, such as Friston's 'predictive coding' (2003; 2012; and Friston et al. 2010), suggest that the mind strives to minimise surprise in order to establish a stable sense of the probabilities of the world. The probability design of a fictional narrative, however, is often engineered to overthrow readers' predictions and the new observations force them to reconsider its probabilities. It does not seem a coincidence that early modern narrative forms, like the French romance and the eighteenth-century novel, which both experiment in lengthy prose plots, feature surprise prominently.

Later in the novel, Evelina gets surprised herself: she receives a letter from Lord Orville in which he proposes a clandestine correspondence - a deeply inappropriate advance which signals a lack of respect for her. What she thought likely before (that Orville is a serious suitor for her hand in marriage) seems suddenly much less likely. This letter is placed close to the end of the second volume of the novel, ${ }^{2}$ and readers are left with no account for Orville's surprising change of character. Yet at stake here seems to me a range of possible explanations for which the respective probability needs to be established rather than the gap in the narrative. Immediately, Evelina can come up with a number of possible reasons for Orville's behaviour, but none of these seem very satisfactory. Here, the cliffhanger is the point at which surprise tilts into curiosity, and at which readers (and characters) begin a discovery process for new possibilities that suit the observation better.

After a conversation with Sir Clement, another of her suitors, Evelina finally figures out the truth about the letter:

2 Burney's Evelina was published in three volumes. 
But what, my dear Sir, am I to conclude from his strange speeches concerning the letter? Does it not seem as if he was himself the author of it? How else could he be so well acquainted with the contempt it merits? Neither do I know another human being who could serve any interest by such a deception. I remember, too, that just as I had given my own letter to the maid, Sir Clement came into the shop; probably he prevailed upon her, by some bribery, to give it to him, and afterwards, by the same means, to deliver to me an answer of his own writing. Indeed I can in no other manner account for this affair. (Evelina 2008: 358)

Sir Clement's “strange speeches” make Evelina curious, and in the letter to her guardian, she fully develops an alternative scenario, a possibility of what could have happened, for the insulting letter which ultimately has greater probability than a sudden change in Lord Orville's character.

Our sense of probabilities can be understood as so-called 'Bayes' nets', that is, sets of causal links or possibilities connecting events which are weighted with different degrees of probability (see Gopnik et al. 2004; Gopnik and Tenenbaum 2007). In this instance, Evelina's attention is drawn to a possibility in her Bayes' net that she had hitherto ignored: the possibility that not Lord Orville but somebody else wrote the letter. With this new possibility gaining in probability as she reconsiders the course of events, the other possibilities in her Bayes' net, namely that Orville wrote the letter to insult her or to solicit her as a mistress, need to get re-weighted. In other words, she needs to determine how likely it is that the particular causal explanation offered by this possibility explains the events. If Sir Clement had written the letter, then the probability is very high that he knows of its insulting nature (and the probability that he learnt of this some other way are rather slim). If Sir Clement had written the letter, then he was serving his own interest (and there is no one else whom this letter would have served). As Evelina explores the alternative scenario in which Sir Clement intercepts her letter to Orville from her maid and sends his own forged letter back, this possibility gains in probability, because it can explain all events, both the letter and Sir Clement's strange behaviour, in a satisfactory causal fashion that has a very high probability of actually being the case.

The third cognitive effect, suspense, can be observed in the ballroom scene we discussed earlier. How is it all going to turn out for Evelina? Will she send the fop packing or will she end up being embarrassed herself? With every word from the fop, every laugh from the heroine and every stare from Lord Orville, the possibility of Evelina's mortification becomes more and more likely. Various other conceptualisations of suspense point out a similar feature of the phenomenon: In an experiment on problem-solving and suspense in the James Bond novel Casino Royale, Richard Gerrig and Allan Bernardo (1994) removed one escape route after another, thereby making Bond's death at the hands of Le Chiffre more and more likely. In Alfred Hitchcock's classic trope of suspense, we have a bomb ticking 
down under a table, unbeknownst to the characters but in plain view of the audience (see Truffaut 1985). If curiosity, as outlined above, describes the process of exploring new possibilities, then suspense refers to the process in which one of these possibilities gains distinctly in probability, be it through the active exclusion of other possibilities (as in Gerrig and Bernardo) or through the approach of a deadline (as in Truffaut). For the situations in which Evelina, James Bond and the people around Hitchcock's table find themselves, the probability of one outcome in the Bayes' net gets stronger and stronger as suspense mounts.

Because of the discrete definitions often given to them, it might seem as if surprise, curiosity and suspense were three discrete operations. To my knowledge, Sternberg does not explore the potential commensurability of his concepts. As related to Bayesian inference, however, all three cognitive effects can be seen as part of a continuous probability design: surprise arises from new observations, which force readers to reassess previous probabilities; curiosity is the process of reconsidering these possibilities in the Bayes' net and their respective weighting; and suspense ensues when one probability gets weighted more and more strongly in this process. Curiosity and suspense are not necessarily distinguished as looking backward (curiosity) and looking forward (suspense) as in Sternberg's model, because they are not primarily directed at gaps, but constitute reconfigurations of the entire fictional world. Indeed, on a Bayesian account, the processes related to curiosity, that is, processes of establishing possibilities and weighting them with the predictive power of probabilities (which leads to suspense) can be performed for future events as well. Sometimes suspense leads to surprise, such as when a new observation occurs that suggests a possibility that makes everything make sense (something like a surprise twist; in Evelina, the revelation that the nurse has passed off her own child as the heiress explains her father's reluctance to concede to her claims - he thinks she is an impostor) or when it relieves readers from weighting one probability further (such as the 'last second rescue', for example when Sir Clement intervenes as Evelina is harassed in the pleasure garden). One aspect of Bayesian inference runs into another quite naturally as readers explore and configure the probabilities of the fictional world.

In suspense, the connections between probability calculus and the emotional involvement of readers are particularly evident, even though the immersive, empathetic dimension of suspense is often seen as irreconcilable with its cognitive, problem-solving dimension (see Beecher 2007 for an overview of the debate). For a Bayesian perspective on narrative, however, the emotional implications of probability are crucial because they reflect the stake which particular characters (and readers) have in a particular possibility. While we might be reading letter sequences from left to right, developing a Bayesian sense of likely words and feeling very little (see Norris 2006), the ways in which events in the plot affect 
characters have a clear emotional resonance. We like Evelina and want to spare her social disgrace. However, the probability that gets more and more likely in suspense usually ${ }^{3}$ is the one that readers have a strong emotional investment against.

At this point, I should briefly address how Bayesian probability calculus and the recent interest in emotions in cognitive narratology might fit together. Patrick Colm Hogan, in Affective Narratology (2011), distinguishes between different ways in which emotional perceptions and appraisals play out in narrative, which we can also trace in Evelina. As gut-feelings, emotions are constantly experienced (LeDoux 1999) and contribute to our decision-making processes (Damasio 2006). The 'concern-based' nature of emotions (Frijda 2007) leads from immediate, unreflective responses to long-term, considered emotional appraisals. Long-term, goal-based emotional appraisal is also important for the ways in which readers evaluate potential ways in which the story might develop (Oatley 1992). When readers are concerned for Evelina in the ballroom, their response to the different facets of Evelina's exuberance, Lord Orville's surprise and the fop's anger modulate the emotional judgement of probabilities for how the scene will turn out. There are "working anticipations", in Hogan's phrase (2011: 49). Readers may also be worried that Evelina's behaviour harms her "long-term expectancies" (Hogan 2011: 50); the long-term goals of her prospects on the marriage market (for characters in the fictional world) and in the romantic plot (for readers). Just as we saw for probabilities in the previous section, there seems to be continuity between fine-grained embodied emotional judgements and the larger propositional appraisals they feed into.

Such emotional investments form an important part of the probability design of a narrative. They belong not only to moments of suspense, but also to surprise and curiosity. The letter brings an unexpected observation which readers evaluate as negative, whereas the discovery of Lord Orville's innocence is a surprising observation that we evaluate as positive. When Evelina persists in tracing another explanation for the letter, through curiosity, the probability that Lord Orville had nothing to do with writing it is appraised positively (and therefore seems salient) on all levels of emotional involvement: First, Evelina feels love and admiration for him, and the outcome of her Bayesian inference justifies her gut feelings. Second, Sir Clement has been portrayed as a pushy and generally insufferable suitor, and it serves him right that his scheme should be discovered. Indeed, our sense of

3 Suspense in the Bayesian sense can also coincide with a positive emotional appraisal. This is the case, for example, when Evelina approaches the conclusion that Orville did not write the letter (see also below). 
narrative rewards and punishments (see Flesch 2007) is steeped in such emotional appraisals. In the larger scheme of things, Lord Orville serves as the romantic hero of the plot, and Evelina's findings make the happy ending possible again.

The probabilistic and the emotional go hand in hand. For analytical purposes, it makes sense to distinguish between the ways in which these two aspects can be combined: On the one hand, possibilities get weighted with the predictive causal probability of what, given our grasp of the fictional world and previous observations, is most likely to happen. In the ballroom scene in Evelina, that would be her embarrassment and social disgrace. At the same time, possibilities get weighted with the emotional appraisal of what readers want to happen. ${ }^{4}$ Frequently, as in the ballroom scene, readers' emotional investments are at crosspurposes with their probability judgements. A narrative's probability design thereby cues readers to hope for a different probability from the one that the narrative currently establishes and to look out for new observations that prompt revisions of their probabilistic grasp of the storyworld that will get them eventually closer to the desired outcome.

\section{Verisimilitude and the Trajectory of the Plot}

On a Bayesian account, the verisimilitude of the fictional world is malleable. It is not a realist template against which the fictional world is compared, but the probabilistic predictive model developed by readers for the fictional world throughout the narrative. Here lies a significant difference between Bayesian verisimilitude and earlier treatments of the topic.

Jonathan Culler in Structuralist Poetics (1975), for example, describes verisimilitude in terms of the cultural models which texts draw on in order to 'naturalise' their fictional worlds. Culler distinguishes between five levels of verisimilitude: (1) the real world; (2) cultural norms; (3) generic norms; (4) texts reflecting on their own conventions; (5) parody. These levels provide, through the conventions of a genre or mode of writing, then "possibilities of meaning, ways of naturalising the text and giving it a place in the world which our culture defines" (137). Monika Fludernik in Towards a 'Natural' Narratology (1996) turns Culler's

\footnotetext{
4 Baroni's discussion of 'narrative tension' (2007) already stresses the importance of the emotional involvement of readers in surprise, curiosity and suspense. However, Baroni focuses on the overall emotional effects of the plot, comparable to Aristotle's catharsis, whereas my discussion here concerns itself both with the local emotional assessment of particular possibilities and how these build up to the overall trajectory of the plot.
} 
'naturalisation' into 'narrativisation', as readers work with "core schemata from frame theory" (1996: 43), frames of mediation and "access" to the narrative, as well as frames of genre and narration, in order to understand what they read in terms of its narrative. In Fludernik's complex and historically dynamic model, we do not find strange what we read on the page because our minds can integrate it into cognitive, experiential and cultural schemata.

Both Culler's 'naturalisation' and Fludernik's 'narrativisation' are underwritten by generally stable structures or frames. Readers match what they read to these structures in order to make sense. As Culler puts it, "[t]o understand the language of a text is to recognise the world to which it refers” (1975: 135). While readers might select a frame, such as for example conceiving of the voice of a text as a narrator in the third person (see Jahn 1997 for this example), the frame is fixed and regulates in a top-down fashion its predictions. The predictive models of Bayesian inferences, on the other hand, are constantly in the process of being revised and updated. These predictive models draw on readers' cognitive and cultural knowledge to posit their possibilities and weigh their probabilities, but they are conceived as emergent structures which rely on the feedback loop with the text. It is true that frame theory takes the textual evidence into account, too. In this model, readers generally maintain the frame selected (this is the so-called 'primacy effect') unless a clash between the textual information and the frame forces them to replace the frame (this is the so-called 'recency effect'). However, here the bottom-up operation leads to a reattribution of pre-existing frames rather than a development of the existing probabilistic model on the basis of what readers find on the page and how it is paced through the plot. ${ }^{5}$ While there is an exchange between top-down and bottom-up movements in cognition in these models of verisimilitude and 'textual dynamics', the frame-theoretical model generally stresses their distinctness rather than their connection, which is at the core of Bayesian probability design.

Wolfgang Iser voices a similar reservation against Culler's notion of naturalisation through verisimilitude as early as Der Akt des Lesens (1976), published a year after Structuralist Poetics (1975). According to Iser, the reading process is subject to a constant feedback through textual information. Squire Allworthy in Henry Fielding's Tom Jones, for example, does not exactly live up to his name. His judgement is revealed to be faulty and his benevolence is limited by his all-too indulgent belief of other characters' prejudices. Readers have to constantly cor-

5 Jahn (1997) adopts the terms 'primacy effect' and 'recency effect' from Perry's (1979) and Sternberg's (1978) accounts of 'textual dynamics'. However, he inscribes them into a stricter frame-theoretical model. 
rect their assessment of Allworthy's character in a process which Iser compares to the notion of servomechanism from cybernetics (1976: 111). Somewhat like the cruise control of your car relies on error-correction signals, so do readers constantly modify their understanding of what they read on the basis of the evidence of the text rather than simply inscribe it in pre-existing structures through the process of naturalisation. According to Iser, this feedback and self-correction creates an "event" and thereby makes "real" what we read because these processes happen in real time as we read the text (1976: 112). In other words, the verisimilitude of the text emerges not from a matching process with pre-structured models, as in Culler's naturalisation, but from the very interaction of text and reader.

The Bayesian perspective of a feedback loop between a predictive, probabilistic shape of the fictional world and its correction in the plot, which I have put forward here, allows cognitive narratology to catch up with Iser's insights in verisimilitude. As I have detailed elsewhere (Kukkonen forthcoming), the socalled 'second-generation approaches' to cognition (which explore how mind and body work together, situated in natural and cultural environments) are closely entwined with the Bayesian model of reading. Considering these embodied aspects of reading, such as tracing how small-scale bodily and emotional cues feed into larger propositional modes of cognition, offers an important complement to Iser's implied reader who largely operates at the level of social perspectives and worldviews, such as Squire Allworthy's. Taking a second-generation cognitive perspective, it becomes clear that information on characters' bodily and emotional states (such as for example Evelina's turn to Lord Orville) feeds into predictive models that contribute to the larger ideological and propositional issues that Iser foregrounds. Bayesian verisimilitude, then, is an emergent property of the reader's encounter with the probability design of the narrative. It seems real not because it matches preconceptions about the real world, but because it unfolds with (near) real complexity.

How then do we relate these insights on verisimilitude to the question of the trajectory of changing probabilities in Evelina with which I opened the article? Here, it pays to go back further in the history of literary criticism. Drawing on Aristotle, the neoclassical criticism of the seventeenth and eighteenth century defines verisimilitude (or, the 'vraisemblable') as not relying on reality but on readers' judgement of what is probable (see Kremer 2011) and such reasoning works backwards from effects to the probabilistic assessment of causes (see Patey 1984: 87). Burney writes in her preface to Evelina: "To draw characters from nature, though not from life, and to mark the manners of the times, is the attempted plan of the following letters" (2008: 9; original in italics; my emphasis). Evelina does not tell the real story of a young woman in 1770s London, but a story 
which can be judged as verisimilar. Gérard Genette updates the neoclassical definition by conceiving of verisimilitude as "what would be called today an ideology - in other words, a body of maxims and presuppositions that constitutes, simultaneously, a vision of the world and a system of values" (2001: 240). Genette's re-definition informs for example Culler's understanding of verisimilitude. However, Genette also considers the second aspect of neoclassical verisimilitude, namely, reasoning from effects to causes, and his discussion of this phenomenon might help to approach workings of probability design from the angle of verisimilitude.

According to Genette, the function of verisimilitude is explanatory. If a narrative relies on generally accepted maxims for its causal structures, that is, ideologylike verisimilitude, no "commentaries and justifications" (2001: 242) are necessary. Genette develops a distinction between three different kinds of narrative: 1) The "vraisemblable", which relies on an implicit understanding of the probabilities/decorum which governs the world and supplies causes ("The Marquise called for her carriage and took a ride.”); 2)“Motivated narrative”, in which the narrator provides explicit information which supplies a cause for the action and modifies our probability judgement ("The Marquise called for her carriage and went to bed, because she was highly capricious.”); 3) “Arbitrary narrative”, which violates expectations and in which no explanation is provided ("The Marquise called for her carriage and went to bed.”) (2001: 254). The 'judgement exterior to the text' expected, supplied or elicited - leads us to the workings of Bayesian verisimilitude. In the narrative with verisimilitude (type 1), readers can rely on their prior hypotheses; in the arbitrary narrative (type 3), they have to develop new ones. Indeed, when the Marquise calls for her carriage and goes to bed, this sets a curiosity process in motion in which readers try to assess a likely cause for her surprising behaviour. In the narrative with motivation (type 2), readers are given the cause by the narrator, which in turn modifies their probabilistic model of the fictional world. If readers get the cause that the Marquise is capricious, they will expect her to do all kinds of things in line with her capriciousness in the further course of the narrative. Michael Riffaterre has argued that there is no difference between arbitrary and verisimilar narrative because, knowing the proverbial capriciousness of Marquises, readers will in fact always expect them to do something capricious (1990: 6-7). ${ }^{6}$ Still, it seems hard to conceive of a narrative which is entirely predictable and does not supply (or make readers supply) motivations. At some point, readers will find themselves reasoning for a likely cause, seeking to provide an external judgement. A Bayesian perspective moves verisimilitude away

6 My thanks to Göran Rossholm for mentioning Riffaterre to me. 
from a preconceived structure to the developing, probabilistic model where all three of Genette's types can be at play in a given narrative.

Evelina's memory of the "rules of assemblies", for example, is not much use to her in the further development of the scene in the ballroom. After her mortifying realisation, Lord Orville categorically asserts Evelina's innocence, and thereby goes against the social expectations (that also inform Evelina's inferences), according to which a reputable aristocrat would not come to the rescue of a gauche nobody. This behaviour calls for an explanation. Genette, drawing on Valincour, and the famous debate around the vraisemblable in Lafayette's Princess of Cleves, proposes that such "arbitrary narrative" (type 3) highlights the need for the determination of causes by effects (which Genette calls "retrospective determination" 2001: 252) in narrative. In this sense, Evelina is mortified so that Lord Orville can defend her. The seeming arbitrariness is mended by establishing a psychological explanation as an external judgement in the process of reading (such as 'Lord Orville is in love with Evelina'). The probability design of a narrative, then, continually confronts readers with seemingly arbitrary events and asks them to provide new "external judgements" which change the overall verisimilitude of the fictional world (and often, as in this instance, steers the recalibration of probabilities toward the overall trajectory of the plot).

The psychological explanation that Orville acts so unexpectedly because he is in love with Evelina leads readers to establish a possibility which aligns with the desired outcome of the plot. The external judgements, the motivations and causes, which readers entertain, surely depend on the information which they have about the fictional world, but as we have seen, the emotional salience of these events is just as important. As a standard plot develops, the probability design leads readers to modify their probabilistic grasp of the fictional world through their external judgements in such a way that it fits the desired outcome. In readers' Bayes' nets, the weighting through predictive power in probabilities moves closer toward matching that of the weighting of these possibilities through emotional appraisal. With actions such as Lord Orville's, the plot moves the verisimilitude of the fictional world from the (mundane) probabilities at the beginning of the novel to the (brilliant) probabilities at the end of the narrative.

Readers always have an eye on the outcome of the narrative. In Evelina, a novel of manners, they might expect marriage as the ending because of the conventions of the genre, but the probabilities of the fictional world, as they are presented at the beginning of the narrative, make such a prediction seem unlikely. As the plot 
develops, and paces new observations about the fictional world, the probability design of the narrative works towards revising the predictive probabilistic structure of the fictional world so that it fits with the outcome that is emotionally most satisfying. If we consider how a particular event reconfigures readers' Bayes' nets, both in terms of probabilistic judgements and in terms of emotional appraisals, we can then assess what role it plays in the narrative's probability design. If we see the reader's share from a Bayesian perspective, then readers are not simply filling in gaps but entertaining different possibilities of how the narrative is likely to develop. The verisimilitude of the fictional world and the trajectory of the plot are in constant conversation.

Evelina presents a fairly standard case of probability design; readers are led to modify their beliefs about the fictional world through well-paced operations of curiosity, suspense and surprise and move along a trajectory which makes the outcome of the narrative supply the strongest external judgements. Many narratives manipulate this basic probability design to great effect, such as Richardson's Clarissa, in which Lovelace's attempts to make his happy ending more probable end in calamity, Austen's Northanger Abbey, in which the narrator ironically comments on how unlikely the story is that she ends up telling, and Sterne's Tristram Shandy, which develops away from rather than towards a stable set of probabilities for the fictional world.

The process of Bayesian inference and the probability design of a narrative provide a precise way of modelling readers' engagements with the plot and the verisimilitude of the fictional world. In the first instance, this connects with the study of genre, where standardised probability designs are either enacted or varied in those which readers trace for specific texts. In narratology, it could complement the study of plot structures, both in the shape of Emma Kafalenos' (2006) semantic model based on Propp, Bremond and Greimas, and in the shape of Hilary Dannenberg's (2008) 'poetics of coincidence'. Brian Richardson's project of a "Poetics of Probability" (1997, 61-88), in which he considers different models of causation - fantastic, strongly causal or highly coincidental - offers a typology of the kinds of "external judgements" readers are prompted to make and which might educate them - Quixote-like - to conceive of the world (for a while) through a particular probability calculus. A Bayesian approach could also shed light on tropes such as self-fulfilling prophecies and "cheap plot tricks" (Ryan 2009), and reassess them as instances in which readers' probability assessments loop back onto themselves or become fast-tracked to the trajectory of the plot. Finally, the Bayesian process of reading draws attention to the "disnarrated" (Prince 1988) through its constant trade-off between the course of events which readers are led to accept as the most likely and the other possibilities, that is, ways in which the narrative could have gone. 
In this article, I have presented the basic model of a Bayesian understanding of plot and verisimilitude. Frequently, it lead my discussion in the way of the basic issue of literariness that has been dubbed 'canonicity and breech' (by Bruner), which also recurs in the ideas that plot needs to feature an element of disruption (by Todorov) and that literary texts work against automatisation (by Shklovsky; see Herman 2009: 19-21 for a concise overview). A Bayesian perspective understands narrative as working both with and against the drive to stability in the predictive coding of our natural and cultural environments. Readers' Bayesian inferences are activated, accelerated and finally led to a new equilibrium through the probability design of a narrative, starting at the very bottom of textual detail and feeding through loops into the more general trajectory of the plot. This process of revising probabilities is not left to the level of propositional statements about the fictional world and problem-solving through games of question and answer, but it extends to the embodied, immersive reading experience and the emotional investments of readers in the narrative. It may allow us to construct - through narrative - explanations for the unexpected (see Herman 2009: 20-21), but more generally, literary narratives explore and negotiate what we consider possible through probability designs that lead readers to establish new possibilities in their Bayes' nets and to reconsider their predictive power in new and unexpected ways. Indeed, our Bayesian explorations of natural, cultural and fictional environments constantly inform one another. ${ }^{7}$

\section{Works Cited}

Baroni, Raphaël. 2007. La tension narrative : suspense, curiosité et surprise. Collection Poétique. Paris: Seuil.

Beecher, Donald. 2007. “Suspense”. Philosophy and Literature 31.2: 255-279.

Bordwell, David. 1987. Narration in the Fiction Film. London: Routledge.

Brewer, William and Edward Lichtenstein. 1981. "Event Schemas, Story Schemas and Story Grammars”. In: John Long and Alan Baddeley (eds.). Attention and Performance. Volume 9. Hillsdale: Lawrence Erlbaum. 636-679.

Burney, Frances. 2008. Evelina, Or, the History of a Young Lady's Entrance into the World. Ed. Vivien Jones and Edward A. Bloom. Oxford World's Classics. Oxford: Oxford University Press.

7 I would like to thank Emily Troscianko for our discussions around our lectures on "Literature and Your Mind", from which this paper partly emerged, audiences in Oxford and Stockholm, where I presented earlier versions of this paper, as well as Raphaël Baroni, Marco Caracciolo, Jonas Grethlein, Henrik Skov Nielsen and Hans-Ulrich Seeber for their helpful and generous comments. My research has been supported by the Balzan Interdisciplinary Seminar, University of Oxford, the Academy of Finland and the University of Turku. 
Carroll, Noël. 2007. “Narrative Closure”. Philosophical Studies 135: 1-15.

Clark, Andy. 2013. "Whatever next? Predictive Brains, Situated Agents, and the Future of Cognitive Science". Behavioral and Brain Sciences 36.3: 181-204.

Culler, Jonathan. 1975. Structuralist Poetics: Structuralism, Linguistics and the Study of Literature. London: Routledge \& Kegan Paul.

Damasio, Antonio R. 2006. Descartes' Error : Emotion, Reason and the Human Brain. London: Vintage.

Dannenberg, Hilary P. 2008. Coincidence and Counterfactuality: Plotting Time and Space in Narrative Fiction. Lincoln: University of Nebraska Press.

Flesch, William. 2007. Comeuppance: Costly Signaling, Altruistic Punishment, and Other Biological Components of Fiction. Cambridge: Harvard University Press.

Fludernik, Monika. 1996. Towards a 'Natural' Narratology. London: Routledge.

Frijda, Nico H. 2007. The Laws of Emotion. Mahwah, NJ: Lawrence Erlbaum.

Friston, Karl. 2003. "Learning and Inference in the Brain”. Neural Networks 16: 1325-1352.

Friston, Karl. 2012. "Prediction, Perception and Agency”. International Journal of Psychophysiology 83: 248-252.

Friston, Karl J., Jean Daunizeau, James Kilner and Stefan J. Kiebel. 2010. “Action and Behaviour: A Free-Energy Formulation”. Biological Cybernetics 102.3: 227-260.

Frith, Christopher D. 2007. Making up the Mind : How the Brain Creates Our Mental World. Oxford: Blackwell.

Genette, Gérard. 2001. “'Vraisemblance’ and Motivation”. Trans. David Gorman. Narrative 9.3: 239-258.

Gerrig, Richard J. and Allan B.I. Bernardo. 1994. "Readers as Problem-Solvers in the Experience of Suspense". Poetics 22.6: 459-472.

Gopnik, Alison, Clark Glymour, David M. Sobel, Laura E. Schulz, Tamar Kushnir and David Danks. 2004. "A Theory of Causal Learning in Children: Causal Maps and Bayes Nets". Psychological Review 111.1: 3-32.

Gopnik, Alison and Joshua B. Tenenbaum. 2007. “Bayesian Networks, Bayesian Learning and Cognitive Development”. Developmental Science 10.3: 281-287.

Herman, David. 2009. Basic Elements of Narrative. Oxford: Wiley-Blackwell.

Hogan, Patrick Colm. 2011. Affective Narratology: The Emotional Structure of Stories. Lincoln: University of Nebraska Press.

Jahn, Manfred. 1997. "Frames, Preferences, and the Reading of Third-Person Narratives: Towards a Cognitive Narratology". Poetics Today 18.4: 441-468.

Kafalenos, Emma. 2006. Narrative Causalities. Columbus: Ohio State University Press.

Kremer, Nathalie. 2011. Vraisemblance et représentation au XVIIIe siècle. Paris: Honoré Champion.

Kukkonen, Karin. Forthcoming. “Presence and Prediction: The Embodied Reader's Cascades of Cognition". Style 48.3.

LeDoux, Joseph E. 1999. The Emotional Brain : The Mysterious Underpinnings of Emotional Life. London: Phoenix.

Norris, Dennis. 2006. “The Bayesian Reader: Explaining Word Recognition as an Optimal Bayesian Decision Process”. Psychological Review 113.2: 327-357.

Oatley, Keith. 1992. Best Laid Schemes: The Psychology of Emotions. Studies in Emotion and Social Interaction. Cambridge: Cambridge University Press.

Patey, Douglas Lane. 1984. Probability and Literary Form: Philosophic Theory and Literary Practice in the Augustan Age. Cambridge: Cambridge University Press. 
Perry, Menakhem. 1979. "Literary Dynamics: How the Order of a Text Creates Its Meanings [With an Analysis of Faulkner's 'A Rose for Emily']”. Poetics Today 1.1/2: 35-64; 311-361.

Prince, Gerald. 1988. “The Disnarrated in Narrative Theory and Criticism”. Style 22.1: 1-8.

Richardson, Brian. 1997. Unlikely Stories : Causality and the Nature of Modern Narrative. Newark: University of Delaware Press.

Riffaterre, Michael. 1990. Fictional Truth. Baltimore: Johns Hopkins University Press.

Ryan, Marie-Laure. 2009. “Cheap Plot Tricks, Plot Holes, and Narrative Design”. Narrative 17.1: $56-75$.

Saffran, Jenny R., Ann Senghas and John C. Trueswell. 2001. "The Acquisition of Language by Children”. Proceedings of the National Academy of Sciences 98.23:12874-12875.

Sternberg, Meir. 1978. Expositional Modes and Temporal Ordering in Fiction. Baltimore: Johns Hopkins University Press.

Sternberg, Meir. 1992. "Telling in Time (II): Chronology, Teleology, Narrativity”. Poetics Today 13.3: 463-541.

Sternberg, Meir. 2001. “How Narrativity Makes a Difference”. Narrative 9.2: 115-122.

Sternberg, Meir. 2003. "Universals of Narrative and Their Cognitivist Fortunes (I)". Poetics Today 24.2: 297-395.

Truffaut, François. 1985. Hitchcock. Rev. ed. New York: Simon \& Schuster. 